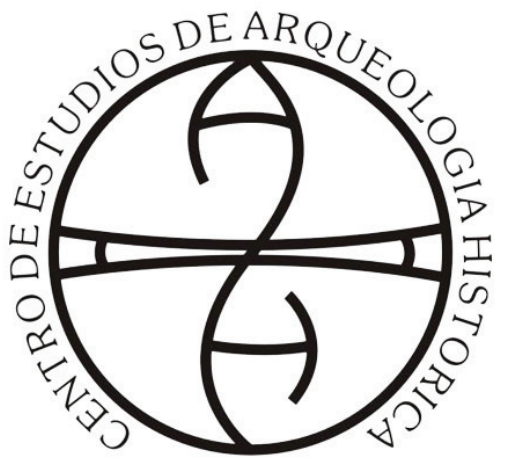

Centro de Estudios de Arqueología Histórica Universidad Nacional de Rosario

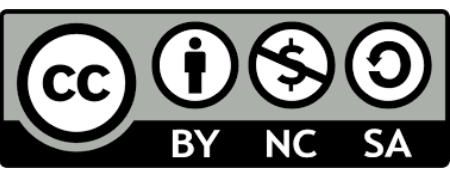

Teoría y Práctica de la Arqueología Histórica Latinoamericana | Año X, Volumen 13 | 2021

Revista del Centro de Estudios de Arqueología Histórica, Facultad de Humanidades y Artes,

Universidad Nacional de Rosario

https://teoriaypracticaah.unr.edu.ar/index.php/index https://rephip.unr.edu.ar/handle/2133/14804

ISSN en línea: 2591-2801

ISSN versión impresa: 2250-866X

Atribución-NoComercial-CompartirIgual 4.0 Internacional (CC BY-NC-SA 4.0)

https://creativecommons.org/licenses/by-nc-sa/4.0/deed.es

Victoria Pedrotta (ID: https://orcid.org/0000-0003-14860215), Vanesa Bagaloni (ID: https://orcid.org/00000002-5444-6302), Bruno A. Pollard (ID: https://orcid. org/0000-0002-0021-5867), Irene C. Bracco (ID: https:// orcid.org/0000-0001-5191-4935), Juan R. Tormo Izaguirre (ID: https://orcid.org/0000-0001-7924-7222), Hernán Tomassini (ID: https://orcid.org/0000-0002-7274-7133), Adolfo C. Eliges (https://orcid.org/0000-0001-5213-2265) y Verónica S. Martí (ID: https://orcid.org/0000-0003-31704601). Arqueología histórica en el espacio fronterizo y rural pampeano-patagónico: trayectorias, avances y desafíos

\title{
ArquEOLOGía histórica EN EL ESPACIO FronTERIzO Y RURAL PAMPEANO-PATAGÓNICO: TRAYECTORIAS, AVANCES Y DESAFÍOS
}

\section{Historical ARCHAEOLOGY AT FRONTIER AND RURAL SPACES IN PAMPA}

\section{AND PATAGONIA REGIONS: TRAJECTORIES, ADVANCES AND CHALLENGES}

\author{
Victoria Pedrotta *, Vanesa Bagaloni **, Bruno A. Pollard ***, Irene C. Bracco ****, \\ Juan R. Tormo Izaguirre *****, Hernán Tomassini $* * * * * *$, Adolfo C. Eliges $* * * * * * *$ \\ y Verónica S. Martí ********
}

\footnotetext{
* CONICET/ Centro de Ciencias Naturales Ambientales y Antropológicas, Fundación de Historia Natural Félix de Azara, Universidad Maimónides - Facultad de Ciencias Naturales y Museo, Universidad Nacional de la Plata. Argentina. vpedrotta@conicet.gov.ar ** CONICET/ Centro de Ciencias Naturales Ambientales y Antropológicas, Fundación de Historia Natural Félix de Azara, Universidad Maimónides - Facultad de Ciencias Naturales y Museo, Universidad Nacional de la Plata. Argentina. bagaloni.vanesa@maimonides. edu

*** Centro de Ciencias Naturales Ambientales y Antropológicas, Fundación de Historia Natural Félix de Azara, Universidad Maimónides. Argentina. bruno.pollard93@live.com.ar

**** Centro de Ciencias Naturales Ambientales y Antropológicas, Fundación de Historia Natural Félix de Azara, Universidad Maimónides. Argentina. icbracco@gmail.com

***** Centro de Ciencias Naturales Ambientales y Antropológicas, Fundación de Historia Natural Félix de Azara, Universidad Maimónides. Argentina. rtormoizaguirre@gmail.com

****** CONICET/Departamento de Humanidades, Universidad Nacional del Sur. Argentina.tomassinihernan@gmail.com ******* CONICET/División Arqueología Museo de La Plata - Facultad de Ciencias Naturales y Museo (Universidad Nacional de La Plata). Argentina. adolfo.eliges@fcnym.unlm.edu.ar

******** Centro de Ciencias Naturales Ambientales y Antropológicas, Fundación de Historia Natural Félix de Azara, Universidad Maimónides. Argentina. veritomarti@gmail.com
}

Arqueología histórica en el espacio fronterizo y rural pampeanopatagónico: trayectorias, avances y desafios

Páginas 27-45
V. Pedrotta, V. Bagaloni, B.A. Pollard,

I.C. Bracco, J.R. TORMo Izaguirre, H. Tomassini, A.C. Eliges y V.S. Martí 


\title{
Resumen
}

En este artículo se presentan las principales líneas de trabajo y actividades desarrolladas por este grupo de investigaciones recientemente conformado que nuclea a investigadores de distintas disciplinas e instituciones. El eje común de todos los proyectos se centra en abordar el proceso de avance y construcción de las fronteras del Imperio Español (en el período colonial) y del Estado (etapa post-independentista) en interacción con las sociedades indígenas en la región pampeana-norpatagónica hasta la conquista militar de fines del siglo XIX. A través de identificar e interpretar los distintos mecanismos materiales, institucionales y simbólicos desplegados por la Corona, el Estado y parte de la población eurocriolla, buscamos comprender las transformaciones espaciales y paisajísticas del territorio que conformó dicho espacio fronterizo y rural. El conjunto de proyectos se caracteriza por presentar novedosas técnicas de detección de sitios y líneas analíticas en el estudio de la cultura material. Asimismo, hemos desarrollado diversas actividades de divulgación científica y de extensión hacia y con las comunidades a distintas escalas -locales, regionales, nacionales e internacionales-. Entre éstas destacamos charlas, talleres, elaboración de material educativo y acompañamiento a las comunidades involucradas en las áreas de trabajo así como acciones en conjunto referidas al cuidado del patrimonio arqueológico. Desde la arqueología histórica, con la integración crítica de distintos tipos de registros, buscamos realizar aportes al conocimiento arqueológico e histórico, local y regional, sobre el complejo y vigente tema de las fronteras.

Palabras clave: fronteras; mundo rural; Pampa; Norpatagonia; siglos XVIII-XIX.

\begin{abstract}
This article presents the main lines of research and activities developed by a newly formed team that brings researchers from different disciplines and institutions together. All the projects have in common the focus on the process of expansion and construction of the frontiers of the Spanish Empire (in the Colonial period) and the State (post-independence stage) in interaction with the indigenous societies of the Pampean-North Patagonian region until the military conquest of the late nineteenth century. Through the identification and interpretation of different materials, institutional and symbolic mechanisms deployed by the Crown, the State and part of the Euro-Creole population, we seek to understand the landscape transformations of border and rural territories. For the development of these projects, innovative site detection techniques and analytical lines are used in the study of material culture. Likewise, we made various scientific divulgation activities for and with communities at different scales -local, regional, national and international-. Among those, we would like to highlight conferences, workshops, educational material and accompaniment to the communities of the studied areas as well as conjoined actions related to the preservation of the archaeological heritage. Through historical archeology and the critical integration of different types of records, we seek to contribute to archaeological and historical knowledge -local and regional- on the current and complex frontier issue.
\end{abstract}

Keywords: frontiers; rural spaces; Pampa; Northern Patagonia; 18th-19th centuries.

\section{Introducción}

La temática de la frontera está siendo objeto de una profunda revisión desde distintas ciencias humanas y sociales en los últimos años, a la vez que constituye un tópico central para el entendimiento de la historia argentina que dejó huellas en el territorio y la sociedad actual. Hace ya más de treinta años que en Argentina comenzaron las investigaciones arqueológicas sobre sitios localizados en las áreas que

Arqueología histórica en el espacio fronterizo y rural pampeanopatagónico: trayectorias, avances y desafios

Páginas 27-45
V. Pedrotta, V. Bagaloni, B.A. Pollard,

I.C. Bracco, J.R. Tormo Izaguirre, H. Tomassini, A.C. Eliges y V.S. Martí 
funcionaron como fronteras del imperio español -durante el período Colonial- y del estado provincial y nacional -a partir del período Independiente- en la región pampeana y territorios adyacentes. El foco de las investigaciones se puso inicialmente en un conjunto de fuertes y fortines bonaerenses -emplazamientos militares fronterizos típicos -de mediados del siglo XIX, que luego fue complementado por el abordaje de una variedad de asentamientos -puestos, estancias, pulperías, postas, tolderías, colonias agrícolas, entre otros- cuyo entramado fue configurando el paisaje rural en estrecha vinculación con la expansión fronteriza. Dentro de este marco, nuestro grupo de investigación trabaja de manera interdisciplinaria en el estudio arqueológico de un conjunto de problemas vinculados a la formación y el avance de las fronteras y los ámbitos rurales en la pampa bonaerense y norte de la Patagonia, pensados como procesos históricos de larga duración en el marco global del colonialismo, la expansión capitalista y la formación del mundo moderno.

Se presenta aquí una actualización de las principales líneas de trabajo y actividades que se desarrollan desde el grupo de investigación en Arqueología Histórica. El mismo se formalizó recientemente dentro del Departamento de Arqueología del Centro de Ciencias Naturales, Ambientales y Antropológicas (CCNAA) en la Universidad Maimónides (UMAI), bajo la dirección de la Dra. Victoria Pedrotta (CONICET/UMAI) y se integra actualmente por una investigadora formada CONICET/UMAI, Dra. Vanesa N. Bagaloni; un becario doctoral CONICET/UMAI, Lic. Axel Rex Weissel; dos becarios doctorales en articulación con otras instituciones donde están llevando a cabo sus respectivos doctorados: Lic. Adolfo C. Eliges, CONICET/Facultad de Ciencias Naturales y Museo de la Universidad Nacional de La Plata y Lic. Hernán Tomassini, CONICET/Universidad Nacional de Sur; cuatro pasantes estudiantes avanzados de las carreras de Arqueología, Bruno A. Pollard e Irene C. Bracco de la Facultad de Filosofía y Letras de la Universidad de Buenos Aires, Verónica S. Martí y Juan R. Tormo Izaguirre de la Facultad de Ciencias Naturales y Museo de la Universidad Nacional de La Plata. Asimismo, permanentemente se cuenta con la colaboración de diversos especialistas para proyectos puntuales y/o tareas específicas (conservación, análisis de materiales, prospecciones geofísicas y actividades de divulgación, entre otras).

Primero, se exponen las principales líneas de indagación que actualmente lleva a cabo el equipo, destacando sus objetivos, los problemas abordados y los avances más relevantes que se han realizado. Luego, se comenta la aplicación de novedosas estrategias metodológicas a las actividades de trabajo de campo, así como las técnicas analíticas orientadas al estudio de los restos materiales que con mayor frecuencia aparecen en los diferentes contextos arqueológicos investigados y sus aportes principales. Por último, se mencionan brevemente algunas experiencias de trabajo en diversas localidades, vinculadas a actividades de divulgación científica y extensión.

\section{Principales líneas de investigación}

Como se señaló, el eje central que articula al trabajo de este equipo de investigación es la comprensión del proceso de construcción y significación del territorio, a través del despliegue de mecanismos materiales, institucionales y simbólicos por parte del Estado en interacción con las sociedades indígenas y la población rural, atendiendo a distintas dimensiones del espacio fronterizo y rural pampeano-norpatagónico, así como sus particularidades socio-demográficas y étnicas. El proceso de avance de las fronteras fue un elemento central en las formas de habitar, disputar, controlar y representar el territorio por parte de distintos agentes y sectores sociales y étnicos, siendo por ello unidades de análisis adecuadas para entender la construcción territorial que finalmente llevó a cabo el Estado-Nación (Benedetti, 2007). La frontera debe ser pensada en simultáneo como un hecho social, una consecuencia y un proceso histórico,

Arqueología histórica en el espacio fronterizo y rural pampeanopatagónico: trayectorias, avances y desafios

Páginas 27-45
V. Pedrotta, V. Bagaloni, B.A. Pollard,

I.C. Bracco, J.R. Tormo Izaguirre, H. Tomassini, A.C. Eliges y V.S. Martí 
que comprende a la sociedad hispano-criolla, la europea y la población indígena (Cusick, 1998; Ratto, 2001). En este contexto se están desarrollando proyectos puntuales que abordan temas, áreas y períodos específicos; ellos articulan líneas de investigación que se llevan a cabo desde hace varios años en la zona de Tapalqué, Azul y Olavarría y en la traza de la Frontera Sur y Costa Sur bonaerense, con otros tres proyectos que comenzaron recientemente en sectores que también formaron las "fronteras interiores" en distintos momentos del siglo XIX: el eje de la primera expansión al sur del Río Salado sobre los partidos de Castelli, Dolores y Maipú, la zona de Bahía Blanca y cursos fluviales del sudoeste bonaerense y el emplazamiento de Choele Choel al norte de la Patagonia (Figura 1).

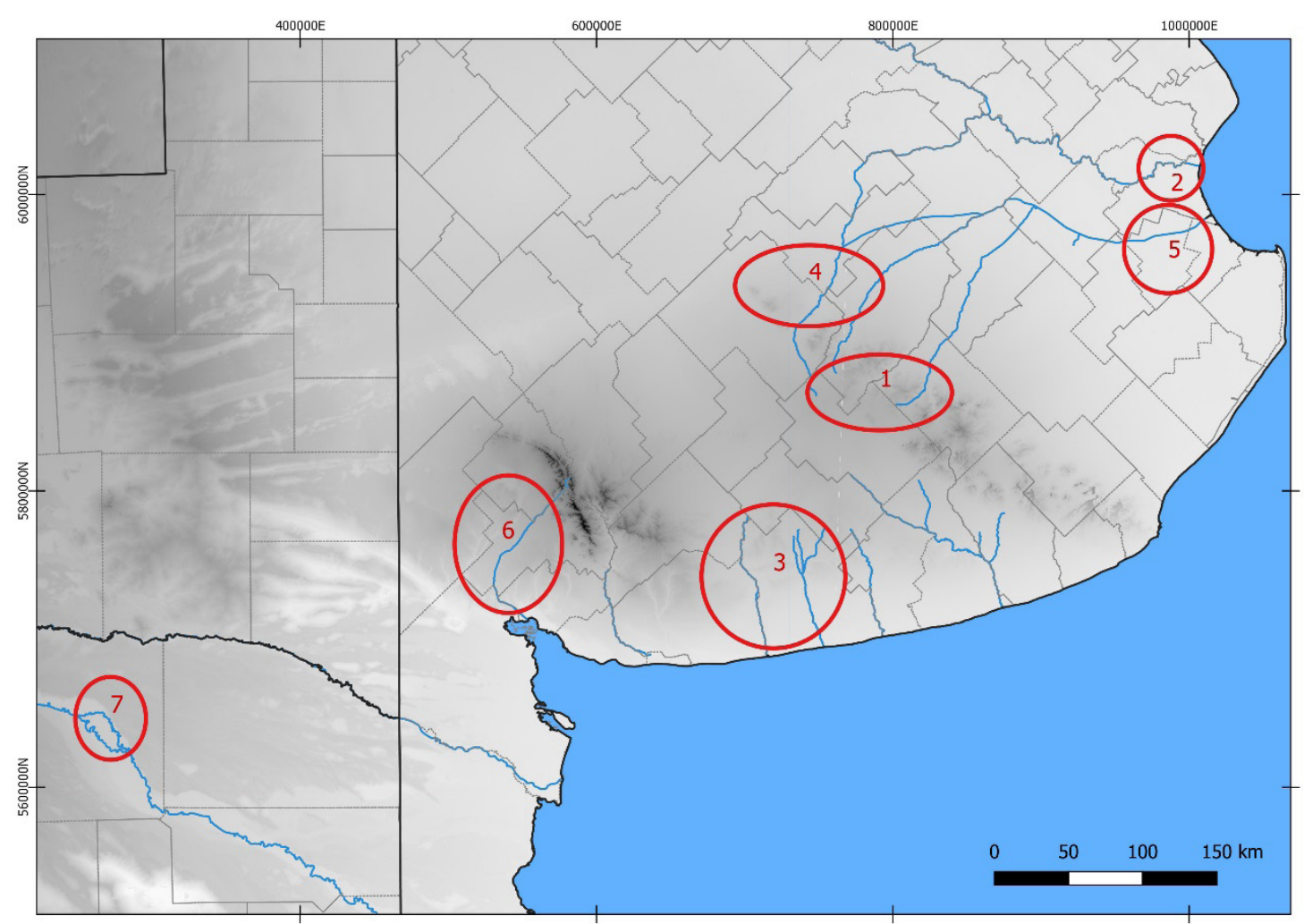

Figura 1. Ubicación aproximada de los proyectos de investigación en curso.

Los proyectos que actualmente se llevan a cabo son los siguientes:

1) "Paisajes indígenas construidos en las sierras bonaerenses. Los corrales de piedra del Sistema de Tandilia desde una perspectiva arqueológica". Dirigido por V. Pedrotta, se centra en el estudio del origen, la cronología y la función de un diverso conjunto de más de 60 construcciones hechas en pirca localizadas en las Sierras del Azul, la Sierra Alta de Vela y la cuenca del arroyo Chapaleofú, así como de las relaciones espaciales que guardan entre sí y con respecto al ambiente donde se hallan emplazadas, indagando las lógicas de construcción de ese paisaje serrano. Esta zona formó parte de los territorios indígenas autónomos hasta la década de 1820 y fue un escenario de intensa interacción y comercio intra

Arqueología histórica en el espacio fronterizo y rural pampeanopatagónico: trayectorias, avances y desafios

Páginas 27-45 
e interétnico dentro de la frontera sur bonaerense. Las grandes construcciones de pirca están asociadas a las actividades de captura de ganado mayor (vacuno y equino) y cría de ovinos que se desarrollaron intensamente en la zona como consecuencia de la multiplicación de las especies domésticas introducidas por los españoles en el siglo XVI.

El abordaje metodológico que está llevando a cabo articula las siguientes líneas de evidencia: fuentes documentales y cartográficas, aerofotointerpretación, relevamientos topográficos y planimétricos, análisis químicos del suelo, prospecciones, recolecciones de superficie, sondeos y excavaciones arqueológicas (Duguine, Pedrotta y Bagaloni, 2009; Pedrotta, Bagaloni y Duguine, 2012). Sobre esta base se concretaron avances en el conocimiento de las estrategias indígenas de explotación de los recursos y la construcción social del paisaje en las sierras septentrionales bonaerenses (Pedrotta, 2016), en las formas en que éstas se articularon en el espacio regional y extra-regional (Pedrotta, 2013), así como en la preservación del patrimonio arqueológico posthispánico provincial (Pedrotta, 2009).

2) “Arqueología de la expansión colonial al sur del Río Salado: la reducción Nuestra Señora de la Concepción de los Indios Pampas y el Rincón de López”. Bajo la dirección de V. Pedrotta, se orienta a comprender el avance de la frontera hispanocriolla tardocolonial producido en 1740 a partir de la fundación de la reducción jesuítica así como el impacto de esa experiencia misional, de casi 13 años, como estrategia pacífica de evangelización de las poblaciones indígenas locales. Esta reducción fue el primer asentamiento español que traspuso el río Salado - que había funcionado hasta entonces como límite natural del territorio efectivamente poblado por los españoles- y fue sucedido por la instalación de la estancia agropecuaria de Clemente López Osornio durante el tercer cuarto del siglo XVIII, en tierras del actual partido de Castelli.

Al integrar críticamente la información generada mediante el análisis intensivo del corpus documental -que ya se fue completado en su mayoría (Pedrotta, 2017)- con los resultados de las pesquisas arqueológicas, se abordan problemas referidos al modo de vida de quienes habitaron el espacio multiétnico de dicha reducción. Se focaliza especialmente en las actividades de subsistencia, los circuitos comerciales y redes de interacción intra e interétnicas de las que formó parte, las actividades productivas, las transformaciones en las tecnologías y patrones de asentamiento indígena tradicionales, entre otros aspectos. Un paso crucial para ello es la elaboración del plano arqueológico del complejo reduccional, a partir de la identificación y el relevamiento de los distintos espacios construidos que lo conformaron y particularmente de los restos edilicios del núcleo del pueblo, por medio de la aplicación de métodos de prospección geofísica en combinación con las técnicas arqueológicas tradicionales. Dada la absoluta desprotección de la que son objeto las ruinas de esta reducción jesuita por parte de las autoridades provinciales y nacionales, con la destrucción consecuente de su valioso patrimonio histórico y arqueológico, es imperioso que se registren, estudien y rescaten los restos materiales que testimonian esta excepcional experiencia misional para la frontera colonial bonaerense (Pedrotta, 2013).

3) "Los asentamientos fronterizos y rurales del sur bonaerense desde un enfoque arqueológico (siglo XIX)". Proyecto dirigido por V. N. Bagaloni, se centra en el estudio de los primeros asentamientos fronterizos y/o rurales en una microrregión del sur bonaerense cuyo estudio sistemático se inició en 2006. Este trabajo tiene como objetivo obtener, analizar y discutir información arqueológica, escrita y gráfica a fin de comprender la constitución y la dinámica de los espacios fronterizos y posteriormente, rurales. Se estudian diversos asentamientos tales como fortines y postas -Pescado, Machado y Tapera de Sabino-, puestos rurales -Las Toscas 3 y Máximo Ortiz- y estancias -La Libertad-, pulperías y casas de negocio -Chapar- que se instalaron en la Frontera Sur y Costa Sur desde mediados del siglo XIX. A excepción de las instalaciones militares, el abordaje arqueológico de estos asentamientos ha tenido escasos antece-

Arqueología histórica en el espacio fronterizo y rural pampeanopatagónico: trayectorias, avances y desafios Páginas 27-45
V. Pedrotta, V. Bagaloni, B.A. Pollard, I.C. Bracco, J.R. TORMo Izaguirre, H. Tomassini, A.C. Eliges y V.S. Martí 
dentes, no sólo en la región pampeana sino en todo el país. El enfoque analítico propuesto enfatiza en el aporte de información original desde una perspectiva arqueológica, antropológica y etnohistórica.

La integración de novedosas metodologías de prospección geofísica (Bagaloni, Perdomo y Ainchil, 2011), de enfoques en el análisis del registro arqueológico -óseo (Bagaloni y Carrascosa Estenoz, 2013), vítreo y cerámico (Bagaloni, 2010, 2014a; Bagaloni y Martí, 2013)- y de las fuentes escritas permite tener una visión regional integrada sobre la conformación de las líneas de frontera que se articularon a partir de la instalación de fortines y postas; la modalidad de expansión territorial, características y cambios de los asentamientos rurales vinculados a actividades agropecuarias; el papel de los comercios minoristas en la vida cotidiana y en los hábitos alimenticios de los pobladores fronterizos y rurales; los circuitos de producción, circulación y consumo de bienes necesarios para la vida en la campaña bonaerense; y la influencia local y regional de la modernización y el capitalismo industrial en la sociedad rural desde mediados de la mencionada centuria (Bagaloni, 2014a, 2014b; Bagaloni y Pedrotta, 2018).

4) "Arqueología e historia de la frontera sur de Buenos Aires durante la segunda mitad del siglo XIX: campos, ejidos y territorio indígena desde una mirada interdisciplinar", bajo la dirección de V. Pedrotta, es un proyecto enfocado al estudio de la territorialidad de los grupos indígenas de la frontera sur durante la segunda mitad del siglo XIX, con foco en la numerosa población de "indios amigos" de la zona de Tapalqué, Azul y Olavarría, en interacción con el proceso de expansión y colonización estatal. Se propone el abordaje conjunto -desde la arqueología y la historia- de problemas vinculados al proceso de construcción, configuración y significación del territorio a través del despliegue de mecanismos materiales, institucionales y simbólicos por parte del Estado, así como la interacción con los grupos sociales locales en su praxis. Se indaga la dinámica histórica de dichos procesos considerando simultáneamente distintas dimensiones del espacio fronterizo y prestando atención a sus particularidades socio-demográficas y étnicas en el lapso abordado.

La magnitud demográfica, la continuidad temporal y la relativa circunscripción espacial que tuvo allí la población de "indios amigos" hasta el último cuarto de la centuria dan cuenta de su importancia dentro del proceso de territorialización e institucionalización del Estado en lo que hoy constituye el centro de la provincia de Buenos Aires. El proyecto toma como eje los procesos de construcción, delimitación y representación del territorio, contemplando de forma integrada: los pueblos y ejidos, las zonas rurales y las tierras indígenas. Se articulan la metodología y las técnicas analíticas de la historia y la arqueología histórica, enfatizando en la diversidad, el contraste, las tensiones y la complementariedad de las fuentes de evidencia (cartográfica, documental, iconográfica, material, etc.), mediante su estudio interdisciplinario a distintas escalas (Lanteri y Pedrotta, 2012, 2018; Pedrotta y Lanteri, 2020).

Arqueología histórica en el espacio fronterizo y rural pampeanopatagónico: trayectorias, avances y desafios

Páginas 27-45
V. Pedrotta, V. Bagaloni, B.A. Pollard,

I.C. Bracco, J.R. TORMo Izaguirre, H. TOMASSINI, A.C. Eliges y V.S. Martí 


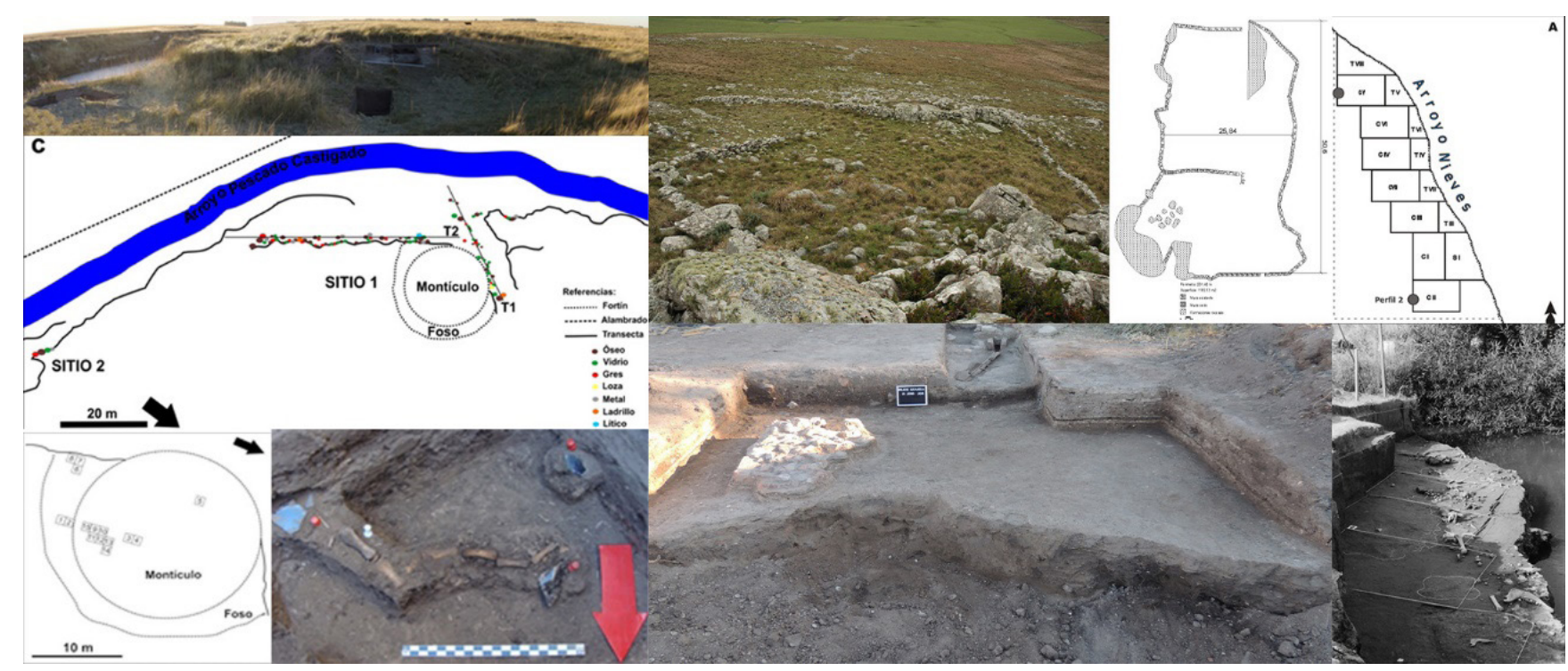

Figura 2. Imágenes y plantas de algunos sitios arqueológicos estudiados.

5) "Arqueología al sur del río Salado: el espacio fronterizo y rural en la primera mitad del siglo XIX". Dirigido por V. N. Bagaloni y V. Pedrotta, constituye el primer estudio arqueológico de los asentamientos asociados al ciclo inicial de expansión de la frontera del período republicano a principios del siglo XIX, por dentro y fuera de la línea oficial de frontera, en los actuales partidos bonaerenses de Dolores y Maipú (Bagaloni y Pedrotta, 2017; León y Bagaloni, 2020). En esta investigación se analizan las formas de ocupación y apropiación del territorio por parte de la sociedad hispano-criolla; la conformación de las líneas de frontera que se articularon a partir de fundaciones militares oficiales y avances civiles espontáneos; las características y cambios de los asentamientos fronterizos/rurales vinculados a actividades agropecuarias; la inserción de mano de obra indígena en estos ámbitos; el papel de los comercios minoristas en la vida cotidiana y en los hábitos alimenticios de los pobladores y la configuración de los primeros pueblos, entre otras cuestiones. El objetivo es caracterizar las ocupaciones hispano-criollas e indígenas de la microrregión y aportar nuevos elementos para entender las características, dinámicas y funciones de los espacios fronterizos y rurales, así como las relaciones interétnicas que allí se sucedieron y que implicaron un gran abanico de hechos históricos, como el "Tratado de Miraflores" que se suscribió en la estancia homónima de Ramos Mejía en 1820. Entre los sitios más relevantes están el Fuerte Kakel Huincul (1815-1827), la propia estancia Miraflores y el presidio de Las Bruscas o Santa Elena (1817-1821), donde las prospecciones geofísicas y arqueológicas comenzaron recientemente (Bagaloni, Pedrotta, Bracco, Pollard y Tormo Izaguirre, 2019). Asimismo, se llevó a cabo la búsqueda de información histórica, etnohistórica y el relevamiento de fuentes escritas y gráficas en repositorios de alcance regional, provincial y nacional.

6) “Arqueología de la ocupación del espacio y construcción del paisaje rural en el sudoeste bonaerense (1830-1890)". Investigación doctoral del Lic. H. Tomassini, busca analizar el proceso de ocupación del espacio y la construcción del paisaje rural en el siglo XIX en una microrregión del sudoeste bonaerense que incluye a los partidos de Bahía Blanca, Cnel. Rosales, Monte Hermoso y sectores de Cnel. Dorrego y Cnel. Pringles para contribuir al conocimiento de la historia local y regional desde un enfoque poco

Arqueología histórica en el espacio fronterizo y rural pampeanopatagónico: trayectorias, avances y desafios

Páginas 27-45 
usado. Se busca estudiar los modos en los que el Estado y sectores de la sociedad euro-criolla impusieron su modalidad espacial y control territorial, decisiones que se tomaron considerando tanto las acciones de los otros actores protagonistas como las diversas parcialidades indígenas que actuaban en la región. En la conformación de este espacio fronterizo, el uso del paisaje como eje organizador fue un factor esencial. Luego de algunas expediciones de reconocimiento, en 1828 inició en el área la presencia estatal con el establecimiento de la Fortaleza Protectora Argentina, enclave militar que luego dio lugar a la ciudad de Bahía Blanca. Las estrategias usadas, que variaron según la coyuntura política, se centraron en la demarcación de líneas de frontera y su militarización a través del establecimiento de fuertes, fortines y zanjas; y en el desarrollo de instalaciones productivas como chacras y estancias; colonias de poblamiento, casas de negocio, comercios rurales y pulperías.

Para comprender estos procesos se integran distintas líneas de evidencia provenientes del registro material y las fuentes escritas (documentos, cartografías, mensuras, planos, entre otros). Esta perspectiva interdisciplinar permite visualizar la continuidad y los cambios del proceso histórico desde el poblamiento regional inicial, los momentos de contacto hispano-indígena y la dinámica de las relaciones interétnicas entre la sociedad criolla y las poblaciones originarias durante el siglo XIX. Las actividades de campo y la revisión de la documentación en distintos archivos (locales, provinciales y nacionales) posibilitaron establecer algunas conclusiones parciales. En tal sentido, los puntos relevantes para ser ocupados fueron aquellos más cercanos al fuerte y sus cursos fluviales adyacentes, por las posibilidades de protección y de regadío que brindaban, verificándose estos asentamientos desde el establecimiento de la Fortaleza. Por otro lado, el registro material y los sitios excavados hasta el momento evidencian una mayor presencia de instalaciones comerciales como pulperías y boliches (Tomassini y Weimann, 2020), aspecto coincidente con la caracterización de Bahía Blanca como factoría comercial para este período.

7) "Localización y caracterización del 'Segundo Pueblo Avellaneda' (Choele Choel, Provincia de Río Negro, 1879-1882)”. Investigación doctoral en desarrollo del Lic. A. Eliges, que tiene como objetivo identificar arqueológicamente al "Segundo Pueblo Avellaneda", primer emplazamiento urbano constituido en el territorio patagónico como parte de la denominada "Campaña del Desierto". Esta ocupación se hizo efectiva en 1879, en el marco del traslado de las fronteras nacionales hasta la costa del Río Negro, para lo cual se requería conquistar y ocupar la isla de Choele Choel en el valle medio, considerada como un enclave fundamental para las comunicaciones y logística indígenas. El Pueblo Avellaneda se fundó el 9 de julio de ese año y se constituyó como cabecera de las operaciones militares programadas. Una fuerte inundación forzó su traslado hacia un terreno más elevado, situado a $2.5 \mathrm{~km}$ al NE de la actual ciudad de Choele Choel, conocido como Pampa de los Molinos, lugar en el que funcionó hasta mediados de 1882 (Eliges, 2017a). Este último traslado implicó un abrupto abandono del pueblo, del que quedaron unas 30 ha de ruinas que constituyen una referencia identitaria omnipresente para las posteriores generaciones de vecinos choelenses y una ventana hacia el pasado que permite analizar la cultura material de un arquetipo de pueblo de frontera que habría de replicarse en muchas de las siguientes ciudades levantadas por las fuerzas expedicionarias. Sin embargo, no existían investigaciones sistemáticas que permitieran unificar las distintas líneas de evidencia documentales, fotográficas, cartográficas y arqueológicas, junto con una memoria social regional fuertemente influenciada por un relato hegemónico castrense (Eliges, 2017b). Por ello el objetivo es delimitar la ubicación y traza del pueblo, analizar su organización espacial y dinámica urbana, e indagar sobre aspectos de su vida cotidiana.

Luego del estudio de distintas fuentes documentales se consiguió el único mapa de época sobre el pueblo, realizado por el subteniente J. Rohde. Se procedió a su georreferenciación, para lo cual se están haciendo estudios geoarqueológicos con el fin de encontrar las similitudes de terreno necesarias en este

Arqueología histórica en el espacio fronterizo y rural pampeanopatagónico: trayectorias, avances y desafios

Páginas 27-45
V. Pedrotta, V. Bagaloni, B.A. Pollard,

I.C. Bracco, J.R. TORMo Izaguirre, H. Tomassini, A.C. Eliges y V.S. Martí 
procedimiento y para dar cuenta de las inconsistencias encontradas a la luz de los procesos postdepositacionales naturales y antrópicos que actúan en el área (Eliges, 2017a). Ya se realizaron varias prospecciones que permitieron delimitar el área del yacimiento y que habilitaron nuevas líneas de investigación en relación con los efectos de la dinámica fluvial sobre el sitio. Esta triangulación de fuentes posibilitó la identificación cartográfica de una serie de "vistas" del Pueblo Avellaneda que forma parte del fondo Zeballos del archivo del complejo museográfico provincial "Enrique Udaondo" (Eliges, 2021). También se está analizando un importante conjunto de bienes patrimoniales proveniente de las intervenciones sistemáticas en el campo y del relevo de los materiales resguardados en museos regionales y colecciones privadas locales, lo que permite estudiar pautas de consumo y la inscripción del pueblo en los circuitos de producción y distribución de bienes industrializados de fines del siglo XIX (Eliges, 2016).

\section{Entre el registro documental y el arqueológico}

Si bien con particularidades en función de los distintos proyectos, en todos ellos "el campo" consiste en la articulación del trabajo de archivo y las tareas arqueológicas en el terreno. Dentro del primero, se destaca la búsqueda y el relevamiento sistemático de fuentes escritas y gráficas como un primer acercamiento microrregional para la localización de asentamientos -tanto indígenas como criollos- y para comprender la evolución de las tierras públicas y privadas en el marco de los procesos de construcción territorial. En este sentido, amerita mencionar el uso pionero de técnicas de aerofotointerpretación para la identificación de construcciones de piedra situadas en el sistema de Tandilia, cuyos resultados significativos permitieron no sólo planificar eficientemente su relevamiento en el terreno sino también conocer la existencia de edificaciones que actualmente están destruidas (Duguine, et al., 2009). Otro destacable caso es el análisis retrospectivo de fuentes cartográficas inéditas -duplicados de mensura de las propiedades rurales y planos regionales del siglo XIX- yuxtapuestas a imágenes satelitales de las Sierras del Azul empleadas para estudiar los extensos tramos de muros de piedra que allí se localizan, y evaluar su función a modo de linderos entre distintas propiedades rurales o como tecnología agropecuaria para el encierro de ganado (Pedrotta y Duguine, 2013). Asimismo, el registro y análisis de planos, mapas y duplicados de mensuras de la frontera sur bonaerense permitió estimar la variedad de los asentamientos fronterizos y rurales factibles de ser hallados arqueológicamente y contrastar con la visibilidad y la localización de los mismos en el terreno (Bagaloni, 2014a). Es relevante también el caso del pueblo Avellaneda, cuyo estudio se realiza mediante la triangulación de fuentes documentales que posibilitó georreferenciar material cartográfico y fotográfico contemporáneo al pueblo, para lo cual se están efectuando estudios geoarqueológicos y de análisis espacial con la asistencia de herramientas GIS y de métodos de prospección electromagnéticos. A futuro se llevará a cabo el levantamiento topográfico de este sitio por medio del uso complementario de drones y equipos ópticos tradicionales (teodolito electrónico y nivel óptico).

Además de las actividades de campo desarrolladas habitualmente en investigaciones de arqueología histórica, es menester destacar las prospecciones geofísicas novedosas para la región pampeana en la búsqueda del primer asentamiento de la reducción jesuita Nuestra Señora de la Concepción de los Pampas, y más recientemente en la estancia La Libertad, el fortín Machado y el presidio Las Bruscas (Pedrotta, 2017; Bagaloni, et al., 2011, 2019). El primero de estos trabajos fue llevado a cabo por los geofísicos J. Gianibelli y R. Cabassi, de la Facultad de Ciencias Astronómicas y Geofísicas de la UNLP, quienes realizaron el relevamiento magnético de una amplia superficie a partir del cual se identificaron sectores con anomalías pero con resultados negativos tras sondeos exploratorios. En los otros sitios arqueológicos se hicieron prospecciones geoeléctricas y magnéticas a cargo del Dr. S. Perdomo y el Lic. G. Mendoza,

Arqueología histórica en el espacio fronterizo y rural pampeanopatagónico: trayectorias, avances y desafios

Páginas 27-45
V. Pedrotta, V. Bagaloni, B.A. Pollard,

I.C. Bracco, J.R. TORMo Izaguirre, H. TOMASSini, A.C. Eliges y V.S. Martí 
de la misma casa de estudios, que permitieron caracterizar rápidamente el terreno e identificar contrastes eléctricos que podrían atribuirse a la presencia de material enterrado -acumulaciones y/o cimientos- o a una alteración en las condiciones naturales del subsuelo, como el movimiento y relleno de suelo para la construcción de un asentamiento -montículo y foso de un fortín, en este caso-. Además, mediante los estudios de susceptibilidad magnética fue posible determinar áreas influenciadas por la actividad humana, como la existencia de objetos de metal -clavos, alambres-, elementos quemados de construcción -ladrillos-, zonas incendiadas, entre otros.

Más recientemente, se utilizaron métodos y técnicas procedentes de la geoarqueología para el estudio de zanjas defensivas localizadas en la ciudad de Bahía Blanca y sus alrededores. De este modo, se analizaron distintas estructuras construidas en el siglo XIX a través del análisis de perfiles sedimentológicos (caracterizando granulometría, color, estructuras sedimentarias, presencia de restos orgánicos, entre otros elementos) y mediciones altimétricas con nivel óptico para confeccionar perfiles topográficos de cada una de ellas. Este tipo de metodología, aplicada al estudio de esas construcciones defensivas, no registra muchos antecedentes en la disciplina. A partir de su aplicación fue posible determinar con detalles sus características morfométricas, las modificaciones y los distintos usos dados a través del tiempo, p.e. el regadío de quintas y chacras (Tomassini, 2020).

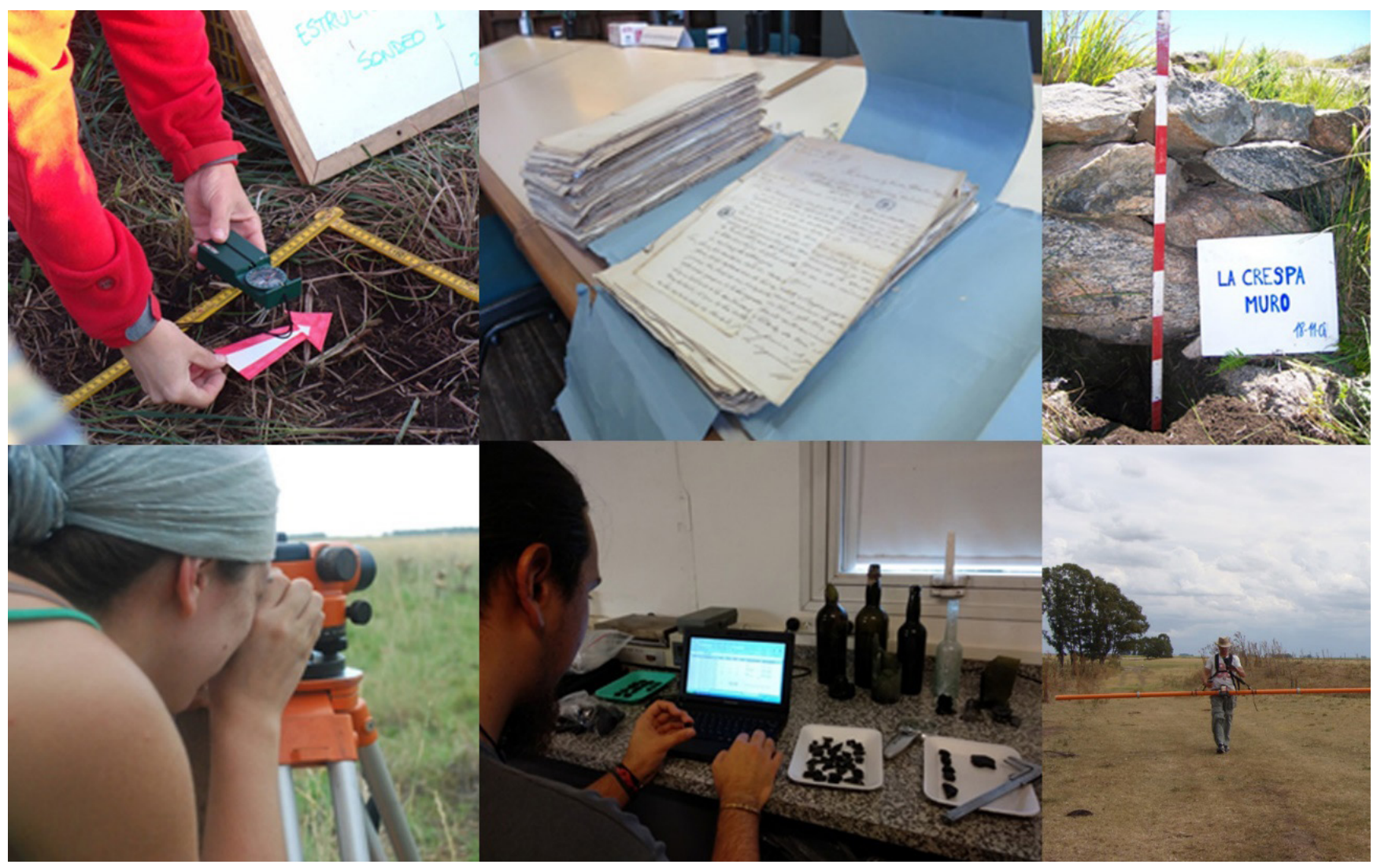

Figura 3. Trabajo de campo y gabinete

Arqueología histórica en el espacio fronterizo y rural pampeanopatagónico: trayectorias, avances y desafios

Páginas 27-45
V. Pedrotta, V. Bagaloni, B.A. Pollard,

I.C. Bracco, J.R. Tormo Izaguirre, H. Tomassini, A.C. Eliges y V.S. Martí 


\section{Líneas analíticas en el estudio de los materiales arqueológicos}

En relación con el trabajo de laboratorio, si bien se utilizan habitualmente los manuales y catálogos clásicos para el estudio de la variedad de restos materiales que aparecen en los contextos posthispánicos, también se realizaron ciertos aportes metodológicos para el estudio de algunos de ellos, tales como el vidrio, el gres y las lozas, considerando las particularidades de los circuitos de producción, distribución y consumo locales. En este sentido, la formación de los pasantes se ha concentrado en el análisis e interpretación de distintos materiales.

Bruno A. Pollard actualmente está trabajando con el material lítico del Fortín Machado, sitio localizado en el partido bonaerense de Tres Arroyos en el cual se recuperó una gran diversidad de materiales en superficie como fragmentos vítreos, piezas cerámicas de diversa índole, restos óseos y el ya mencionado material lítico (Bagaloni, 2014b). Sobre esta última línea de evidencia recae un interés especial ya que remite a los debates acerca de la aparición de esos objetos en un contexto de expansión de fronteras. Al respecto, se consideran diversas posibilidades, como la relación de coexistencia entre criollos y grupos indígenas o la aplicación de técnicas indígenas para la manufactura de artefactos por parte de los criollos. El conjunto lítico hallado en el Fortín Machado se compone principalmente por lascas en su mayoría de desecho, aunque algunas tienen rastros de uso. Se pudo determinar que varios fragmentos pertenecían a raspadores y raederas, además de la presencia de algunas bolas de boleadora (Bagaloni y Pollard, 2018). Al momento, se está haciendo una base de datos de todo el material lítico sobre la cual poder trabajar y profundizar en las interpretaciones.

Juan R. Tormo Izaguirre está realizando el análisis de los restos arqueofaunísticos posthispánicos del sitio Las Toscas 3 (Bagaloni, 2010, 2014b) y el procesamiento inicial del material arqueológico obtenido en las últimas prospecciones en el Fortín Machado. La localidad arqueológica de Las Toscas se encuentra en la laguna homónima, en el partido de Tres Arroyos. El sitio Las Toscas 3 es un palimpsesto que da cuenta de dos ocupaciones distintas: un primer evento indígena y otro correspondiente a un asentamiento criollo a mediados del siglo XIX. Por medio de recolecciones superficiales se recuperaron fragmentos vítreos -principalmente-, restos óseos, artefactos líticos, ladrillos, metales y cerámicas. Guiado por los lineamientos teóricos y el primer acercamiento al registro arqueofaunístico del sitio (Bagaloni, 2014a), se está trabajando bajo la dirección del Dr. Luis del Papa en la identificación anatómica y taxonómica de los restos óseos, el reconocimiento de las marcas de procesamiento y de las variables tafonómicas involucradas en la formación de sitio. El objetivo es conocer las formas en que aprovecharon estos recursos las poblaciones fronterizas y rurales del sur bonaerense, tanto en el marco de la subsistencia como en el de la progresiva integración de la región a los circuitos capitalistas durante la segunda mitad del siglo XIX. En ese sentido, se buscan evidencias que indiquen el paso de un modo de producción de ganadería extensiva a una de tipo intensivo, obedeciendo a las demandas del mercado internacional al que Argentina pretendía ingresar como productor de materias primas. A su vez, también se indaga el rol que desempeñó la fauna autóctona pampeana y la forma en la que ésta ha complementado la economía de los asentamientos criollos.

Arqueología histórica en el espacio fronterizo y rural pampeanopatagónico: trayectorias, avances y desafios

Páginas 27-45
V. Pedrotta, V. Bagaloni, B.A. Pollard, I.C. Bracco, J.R. Tormo Izaguirre, H. Tomassini, A.C. Eliges y V.S. Martí 


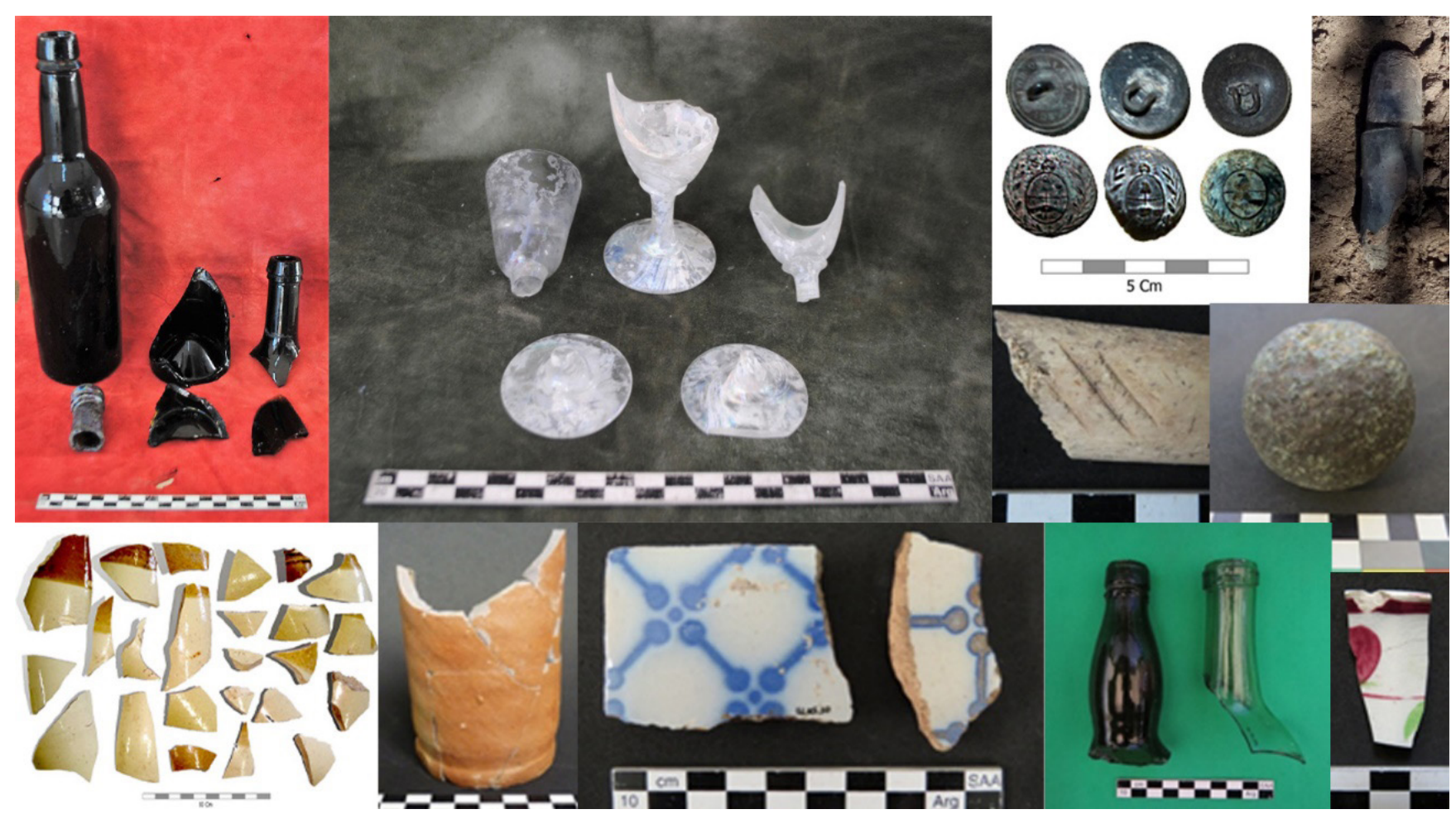

Figura 4. Materiales arqueológicos analizados.

Irene C. Bracco está trabajando con los conjuntos vítreos procedentes de los sitios Tapera de Sabino, Fortín Machado y Las Toscas 3. Siguiendo la metodología propuesta por Pedrotta y Bagaloni (2006), este análisis tiene la finalidad de evaluar la diversidad de artefactos vítreos presentes para poder dar cuenta de los hábitos de consumo y redes de comercio en un contexto de conformación y expansión de fronteras. Puntualmente, se construyó una base de datos para la unificación de criterios de análisis, se estudió el conjunto vítreo del sitio Tapera de Sabino (Bagaloni y Bracco, 2019), están en análisis aquellos hallados de Fortín Machado y se amplió la muestra inicial recuperada en Las Toscas 3. En líneas generales, en todos estos conjuntos hay presentes fragmentos de limetas para ginebra, botellas de espumantes, frascos y tarros, entre otros recipientes.

Verónica Martí trabaja desde hace una década con el estudio de materiales cerámicos -gres, loza y porcelana- de fortines, por ejemplo Pescado, Machado y Tapera de Sabino, los puestos rurales Las Toscas 3 y Máximo Ortiz y la estancia La Libertad. El estudio se orientó primero a generar una base metodológica de análisis macroscópico tanto del gres como de la loza a partir de diversas variables según el tipo de material (Bagaloni y Martí, 2013). En segundo lugar, se analizó el registro cerámico que permitió determinar las características y diversidad de los conjuntos así como identificar su función, procedencia y cronología. Tercero, el estudio de la muestra de gres se integró en una serie de pruebas estadísticas no paramétricas a fin de corroborar hipótesis en relación a la cronología-función de los sitios abordados. Por último, se siguieron diversas líneas de discusión e interpretación intra e intersitio focalizando en los contextos de uso, circulación y descarte de objetos cerámicos, los hábitos cotidianos relacionados con las modas y el status, poder, identidad y género de los pobladores fronterizos y rurales del sur bonaerense durante el siglo XIX.

Arqueología histórica en el espacio fronterizo y rural pampeanopatagónico: trayectorias, avances y desafios

Páginas 27-45 


\section{Experiencias con las comunidades}

En paralelo a estas investigaciones de base, se realizaron diversas actividades, formales y no formales, de divulgación científica y de transferencia hacia y con las comunidades a distintas escalas -locales, regionales, nacionales e internacionales-, así como en algunos casos se concretaron instancias de trabajo conjunto y toma de decisiones. De este modo, se dieron numerosas charlas, talleres y recorridos históricos destinados a sectores educativos de distintos niveles y público en general, por ejemplo, junto con el Instituto Cultural de Bahía Blanca, con los Museos de Arqueología "José Mulazzi” de Tres Arroyos, Museo y Archivo Histórico “E. Squirru” de Azul, Museo y Archivo Regional de Castelli, Museo Municipal de la Piedra "Emma Occhi" de Sierras Bayas y durante el Festival Cervantino que se lleva a cabo periódicamente en Azul. Asimismo, se dieron charlas en las escuelas Polimodal No 40 y Primaria $\mathrm{N}^{\mathrm{o}} 288$ de Choele Choel y en la Escuela Normal $\mathrm{N}^{\mathrm{o}} 1$ de Olavarría. Entre la participación en medios de comunicación, cabe mencionar el uso de redes sociales -"Grupo de Investigaciones Interdisciplinarias de las Fronteras" en Instagram y Facebook- y las entrevistas radiales y televisivas, como en las radios FM La Isla 91.1 MHz, Estación Choele Choel y Prisma FM, 103.1 Mhz; y en el Programa ADN CIENCIA de la Radio UNLP AM 1390 / FM 107.5, así como el canal Caynet de San Cayetano, entre otros.

Algunas de estas actividades se realizaron dentro de proyectos de extensión universitaria. Es el caso de los proyectos FCNyM-UNLP (2009-2010) que enmarcaron diversas tareas de divulgación y transferencia hacia y con las comunidades y museos de los partidos de Tres Arroyos, San Cayetano y Lobería, tales como conferencias, entrevistas radiales y televisivas, y talleres para alumnos de primaria y secundaria, junto con publicaciones en revistas de divulgación (Bagaloni, 2018) y la elaboración de material didáctico. También es el caso del proyecto "Olavarría antes de Olavarría. Un aporte de la arqueología y la paleontología a la identidad cultural regional" (FACSO-UNICEN 2010-2012), por medio del cual se elaboró una muestra itinerante que recorrió los museos de varia localidades de ese partido y estuvo expuesta en la ciudad cabecera (Endere et al., 2014) y de los proyectos de voluntariado universitario "Historia indígena, patrimonio y Campaña" (2015-2016) y "Construcción y re-significación de la historia a través del patrimonio local” (2016-2017), ambos de la FCNyM-UNLP.

En lo que hace a las producciones audiovisuales, cabe mencionar la participación en la serie ficcionada "Lucía. Una miniserie que desafía los relatos sobre nuestra identidad", fruto de un proyecto de divulgación científica subsidiado por el CONICET (FACSO-Producciones, 2015, Olavarría), en el audiovisual "La Trama de la Frontera (Pampa-Patagonia, siglos XVIII a XIX)", producido por el Museo Roca con subsidios del Ministerio de Educación, Cultura, Ciencia y Tecnología de la Nación (2019) y el audiovisual "Yanquetruz - Sangre o Tinta", producido por el Ministerio de Educación, Cultura, Ciencia y Tecnología de la Nación (TEC-TV Producciones, 2019). Así también, a partir de 2020, la participación en distintas plataformas online, como los ciclos "Contando Ciencia", organizado por la Fundación Azara y la Universidad Maimónides y "Fronteras en Perspectiva", organizado por el Museo Roca.

Arqueología histórica en el espacio fronterizo y rural pampeanopatagónico: trayectorias, avances y desafios

Páginas 27-45
V. Pedrotta, V. Bagaloni, B.A. Pollard,

I.C. Bracco, J.R. TORMo Izaguirre, H. TOMASSini, A.C. Eliges y V.S. Martí 


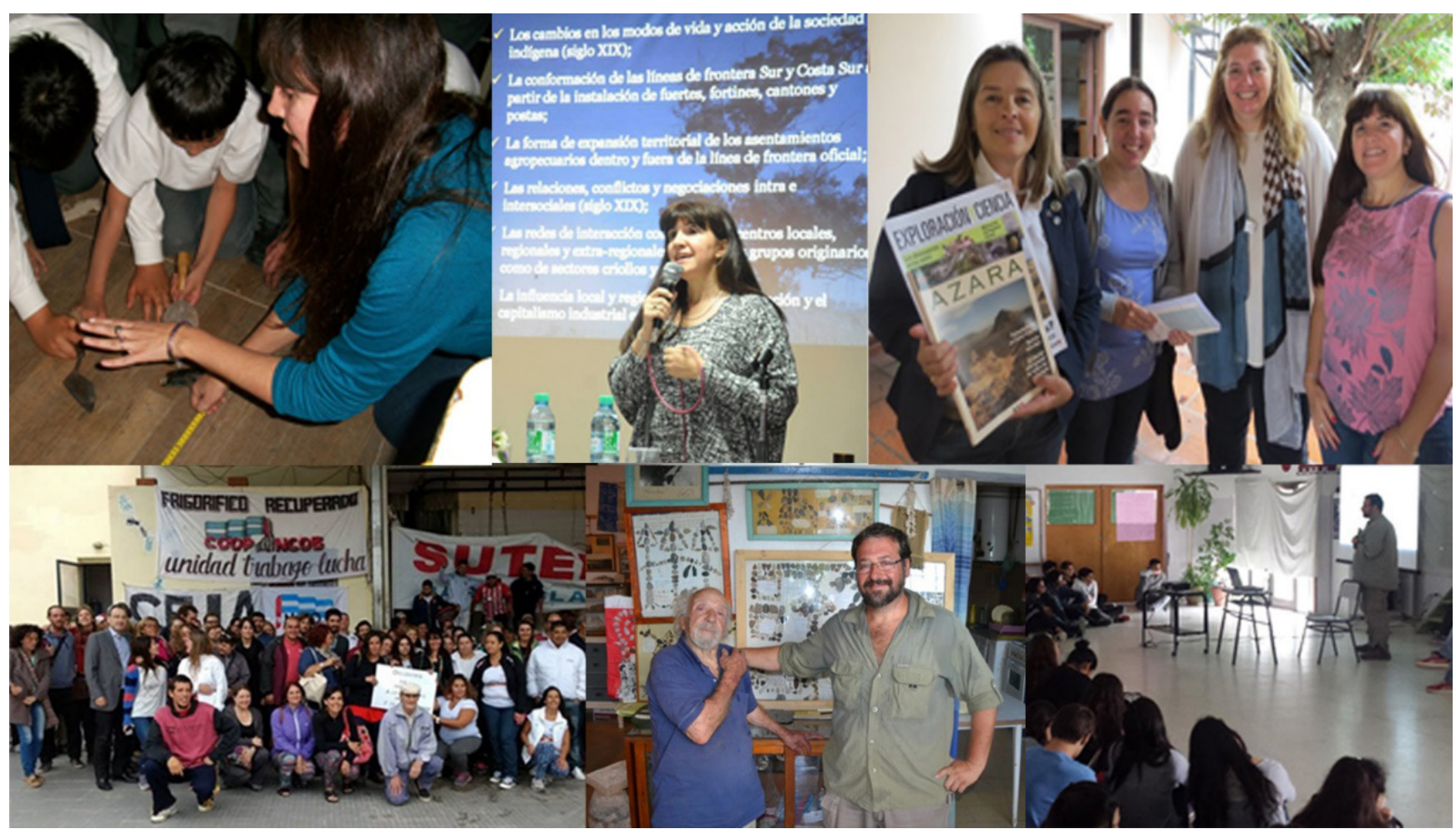

Figura 5. Experiencias con comunidades.

De manera paralela, se desarrollaron actividades en conjunto con distintas comunidades barriales del partido de Bahía Blanca. Con trabajadores y trabajadoras del frigorífico INCOB, una empresa recuperada que es un referente del cooperativismo local, se trabajó en los procesos de producción de conocimiento sobre el pasado y en la toma de decisiones sobre un conjunto de bienes culturales situados dentro de sus instalaciones (Pupio y Tomassini, 2020). En conjunto con el Instituto Cultural de la ciudad, se realizaron actividades educativas infantiles para el día del niño, recorridos históricos por los barrios y charlas para los vecinos y trabajadores. Asimismo, se ha colaborado con otros grupos de investigación dentro de la UNS en el desarrollo de un proyecto educativo para la creación de una escuela primaria donde el personal del frigorífico pudiera instruirse. Por otra parte, se apoyaron los reclamos de restitución de restos humanos que fueron hechos al Museo de la Plata por descendientes de las comunidades indígenas de de Azul y Olavarría (Pedrotta y Bagaloni, 2020).

Como se comentó, la comunidad choelense ha constituido su identidad con un fuerte arraigo en un relato que parte de una concepción civilizatoria construida en articulación con la conquista militar del territorio indígena y con una referencia omnipresente a la cultura material que ha perdurado hasta nuestros días, tanto en el sitio arqueológico como en los bienes patrimoniales rescatados por numerosos vecinos y que hoy son resguardados en colecciones y museos locales. Allí las acciones están orientadas a generar una transferencia a la comunidad local, tanto en la preservación de estos bienes patrimoniales, como en la construcción de conocimiento acerca del pasado regional, con especial énfasis en la ampliación de las perspectivas hacia una mirada más plural de la historia local y trabajando en la puesta en valor de las colecciones museográficas, su catalogación, análisis y normalización para su posterior declaración ante la autoridad provincial. Se realizaron charlas abiertas a la comunidad en escuelas primarias y secundarias y en diversos medios periodísticos locales en conjunto con la Asociación Amigos del Museo Histórico

Arqueología histórica en el espacio fronterizo y rural pampeanopatagónico: trayectorias, avances y desafios

Páginas 27-45
V. Pedrotta, V. Bagaloni, B.A. Pollard,

I.C. Bracco, J.R. Tormo Izaguirre, H. Tomassini, A.C. Eliges y V.S. Martí 
Regional de Choele Choel y con el Municipio de Choele Choel, en las cuales se expusieron los primeros avances de las investigaciones y se propiciaron intercambios con la comunidad respecto del pasado local.

\section{Reflexiones finales}

Como se señaló, las líneas de investigación que se presentaron brevemente tienen como denominador común al proceso de construcción y expansión de las fronteras estatales en interacción con las sociedades indígenas, en el espacio pampeano y norpatagónico, desde la época tardo-colonial y temprano independiente hasta la campaña militar de Roca a fines del siglo XIX. Además del avance en el conocimiento y los saberes puntuales generados por cada proyecto en particular, su integración desde enfoques multidisciplinares y multiescalares posibilita una visión integral y en la larga duración de los procesos y problemas que allí se plantearon. Con respecto a los temas investigados para el período Colonial, se produjeron avances sobre las formas de uso y construcción del paisaje serrano por parte de la sociedades indígenas, en especial las prácticas de cría y traslado de ganado en circuitos regionales y extra-regionales, así como se comenzó a indagar la experiencia misional que llevaron a cabo los jesuitas como dispositivo para evangelizar ciertas parcialidades de "pampas" y "serranos" y la interacción comercial que tuvo como foco las reducciones bonaerenses. Entrado el siglo XIX, se hicieron trabajos de síntesis sobre la conformación de las líneas militares de frontera articuladas a partir de la instalación de fuertes y fortines, se analizaron distintas modalidades de expansión territorial hispano-criollas -como instalación de estancias, asentamiento de "indios amigos", fundación de pueblos, colonias agrícolas y militares, entre otrasque fueron desplegadas a lo largo del tiempo y se avanzó en el conocimiento arqueológico de los establecimientos agropecuarios y sus cambios en función de los modelos productivos regionales. También se abordó el papel de los comercios minoristas en la vida cotidiana de los pobladores fronterizos y rurales explorando sus hábitos de abastecimiento y consumo, se reconocieron los circuitos de producción, circulación y obtención de bienes en la campaña bonaerense y se realizaron aportes desde el conocimiento sistemático de los contextos locales para comprender la influencia de la modernización y el capitalismo industrial en la sociedad rural pampeano-norpatagónica decimonónica.

Asimismo, se hicieron aportes metodológicos, tanto en los trabajos arqueológicos de campo como en el estudio en gabinete de ciertos tipos de materiales específicos. Con respecto a los primeros, la aplicación de diferentes técnicas de prospección geofísicas y las exploraciones a través de sensores remotos con fines arqueológicos en sitios posthispánicos, demostraron ser efectivas en cuanto optimizan los tiempos del trabajo de campo, necesitan un reducido personal, permiten caracterizar rápidamente sectores con restos materiales y así planificar con mayor eficacia las intervenciones arqueológicas e incluso detectar sitios hoy destruidos (Bagaloni et al., 2011). En relación con los segundos, se destacan especialmente las propuestas analíticas para los vidrios, el gres cerámico y las lozas, que son susceptibles de aplicar en otros contextos arqueológicos. En paralelo a estas investigaciones de base se realizaron múltiples acciones formales y no formales de divulgación y transferencia, por medio de diferentes soportes -radiales, audiovisuales, textuales, etc.-, en diversos medios de comunicación y recientemente en las redes sociales, con el acompañamiento de museos locales y regionales y de los respectivos municipios, como así la elaboración de material didáctico para varios niveles educativos.

Más allá de las particularidades de cada proyecto, la perspectiva teórico-metodológica común a todos se sustenta en el gran potencial de la arqueología histórica a partir de su capacidad para integrar críticamente fuentes de evidencia de distinto tipo -restos materiales, fuentes documentales, iconografía, cartografía, obras publicadas, relatos orales, memoria social- en narrativas coherentes y plurales sobre el

Arqueología histórica en el espacio fronterizo y rural pampeanopatagónico: trayectorias, avances y desafios

Páginas 27-45
V. Pedrotta, V. Bagaloni, B.A. Pollard,

I.C. Bracco, J.R. TORMo Izaguirre, H. Tomassini, A.C. Eliges y V.S. Martí 
pasado reciente. Otra preocupación compartida es la vinculación con las comunidades locales y el aporte que se puede realizar desde la disciplina a la construcción de las memorias e identidades sociales. Una buena muestra es de ello es el acompañamiento que se hizo desde el saber académico a los reclamos de restitución de restos humanos efectuados por los descendientes del cacicato Catriel ante el Museo de la Plata. De esta forma, desde la arqueología histórica, que integra evidencias materiales y escritas, junto a la historia oral y las memorias locales, se ha hecho un recorrido que ha generado aportes al conocimiento arqueológico e histórico, local y regional, sobre el complejo y vigente tema de las fronteras.

\section{Referencias bibliográficas}

Bagaloni, V. N. (2010). Desde las orillas... Una comparación de los sitios La Libertad (Pdo. San Cayetano) y Las Toscas (Pdo. Tres Arroyos). En Mamül Mapu: pasado y presente desde la arqueología pampeana, M. Berón, L. Luna, M. Bonomo, C. Montalvo, C. Aranda y M. C. Aizpitarte (eds.), II (215-230). Ayacucho: Libros del Espinillo.

Bagaloni, V. N. (2014a). Arqueología de los asentamientos fronterizos en el sudeste bonaerense (siglo $X I X)$. Tesis doctoral inédita, 409 páginas. Facultad de Ciencias Sociales, UNICEN. Olavarría.

Bagaloni, V. N. (2014b). Arqueología en espacios fronterizos del sudeste bonaerense (siglo XIX): resultados de las primeras prospecciones. Intersecciones en Antropología, 15(1), 05-22.

Bagaloni, V. N. (2018). La vida cotidiana en la frontera. Un recorrido arqueológico por el sur bonaerense. Revista Azara 6: 25-32.

Bagaloni, V. N. y Bracco I. C. (2019). Hábitos en la frontera: Un acercamiento al conjunto vítreo del fortín Tapera de Sabino (Pdo. de Tres Arroyos, Buenos Aires). Revista de Antropología del Museo de Entre Ríos 5 (2): 79-82.

Bagaloni V. N. y L. Carrascosa Estenoz (2013). Estudio de huellas producidas con objetos de metal durante el último cuarto del siglo XIX en el sitio arqueológico La Libertad (partido de San Cayetano, Buenos Aires, Argentina). Revista del Museo de La Plata, Sección Antropología, 13 (87): 375-392.

Bagaloni, V. N. y V. Martí (2013). Ajustes metodológicos para el análisis macroscópico del gres cerámico. Estudio de conjuntos arqueológicos del sudeste bonaerense (siglo XIX). Arqueología 19 (2): 219-243.

Bagaloni, V. N. y V. Pedrotta (2017). Arqueología al sur del río Salado: el espacio fronterizo y rural en la primera mitad del siglo XIX. En Libro de Resúmenes de los Trabajos Presentados en el XVI Congreso de Historia de los Pueblos, pp. 9. Dolores.

Bagaloni, V. N. y V. Pedrotta (2018). Frontiers and Fortlets at the Pampa Region, Argentina. Historical Archaeology 52 (2): 348-371.

Bagaloni, V. N. y B. Pollard (2018). Primeros resultados del análisis lítico del sitio Fortín Machado (partido de Tres Arroyos, provincia de Buenos Aires). Póster presentado en el VII Congreso Nacional de Arqueología Histórica, Rosario.

Arqueología histórica en el espacio fronterizo y rural pampeanopatagónico: trayectorias, avances y desafios

Páginas 27-45
V. Pedrotta, V. Bagaloni, B.A. Pollard, I.C. Bracco, J.R. TORMo Izaguirre, H. TOMASSini, A.C. Eliges y V.S. Martí 
Bagaloni, V. N., Perdomo, S. y Ainchil, J. (2011). Geoelectric and magnetic surveys at La Libertad archaeological site (San Cayetano County, Buenos Aires Province, Argentina): A transdisciplinary approach. Quaternary International 245 (1): 13-24.

Bagaloni, V. N., V. Pedrotta, I. Bracco, B. Pollard y J. R. Tormo Izaguirre (2019). Abordaje arqueológico del presidio de Las Bruscas (1817-1821), Dolores, provincia de Buenos Aires, Argentina. En I Congreso Iberoamericano de Estudios Sociales sobre Conflicto Armado, pp. 94-95. CABA.

Benedetti, A. (2007). El debate sobre las fronteras en la argentina. Estudios Socioterrotoriales. Revista de Geografia VI (6):11-36.

Cusick, J. G. (Editor). (1998). Studies in Culture Contact: Interaction, Culture Change, and Archaeology. Center for Archaeological Investigations, Occasional Paper No. 25. Board of Trustees, Southern Illinois University. Carbondale.

Duguine, L., Pedrotta, V. y Bagaloni, V. (2009). Avances metodológicos en el estudio de las construcciones de pirca de las sierras bonaerenses: las técnicas de aerofotointerpretación. Revista Electrónica de Arqueología Comechingonia Virtual III (1): 63-94.

Eliges, A. (2016). Los materiales del Pueblo Avellaneda (1879-1882) en la colección Salatino Mazzulli (Choele Choel, Pcia. de Río Negro). Serie Monográfica y didáctica - Facultad de Ciencias Naturales e Instituto Miguel Lillo (ISSN: 0327-5868) - Vol.54, 271-277.

Eliges, A. (2017a). La representación cartográfica del "segundo Pueblo Avellaneda", choele choel (Río Negro, 1879-1882). X Jornadas de Arqueología de la Patagonia: libro de resúmenes (pág. 89). Puerto Madryn: Instituto de Diversidad y Evolución Austral.

Eliges, A. (2017b). Avances en la investigación del "segundo Pueblo Avellaneda", Choele Choel (Río Negro, 1879-1882). X Jornadas de Arqueología de la Patagonia: libro de resúmenes (pág. 65). Puerto Madryn: Instituto de Diversidad y Evolución Austral.

Eliges, A. (2021). Un recorrido visual por el Pueblo Avellaneda. Georreferenciación de un conjunto de "vistas" enviadas por J.A. Roca a E.S. Zeballos en 1879. Manuscrito en preparación.

Endere, M. L., Conforti, M. E., Mariano, C., Pedrotta, V., Chaparro, M. G., Mariano, M. y M. J. Laurenz (2014). "PATRIMONIA. Programa Interdisciplinario de Estudios de Patrimonio". En: La Arqueología Pública en Argentina: historias, tendencias y desafios en la construcción de un campo disciplinar, editado por M. Fabra, M. Montenegro y M. E. Zabala, pp. 15-31. Universidad Nacional de Jujuy, S. S. de Jujuy.

Lanteri, S. y V. Pedrotta (2012). Territorialidad indígena y expansión estatal en la frontera bonaerense (segunda mitad del siglo XIX): entre el discurso oficial y la realidad material. Revista Española de Antropología Americana 42 (2): 425-448.

Lanteri, S. y V. Pedrotta (2018). Tierras, armas y política en la frontera sur bonaerense durante la década de 1850. Los "indios amigos", Maicá y Villa Fidelidad. Anuario del Instituto de Historia Argentina $18(1), \mathrm{e} 066$.

León, C. y V. N. Bagaloni (2020). Maipú en perspectiva indígena: Un recorrido arqueológico antes del

Arqueología histórica en el espacio fronterizo y rural pampeanopatagónico: trayectorias, avances y desafios

Páginas 27-45
V. Pedrotta, V. Bagaloni, B.A. Pollard,

I.C. Bracco, J.R. TORMo Izaguirre, H. TOMASSini, A.C. Eliges y V.S. Martí 
Tratado de Miraflores. En: Tratado de Miraflores. Apuntes en el bicentenario del histórico acuerdo de 1820, editado por G. Annessi, pp. 95-112. Centro de Estudios Sociales de Maipú, Buenos Aires.

Pedrotta, V. (2009). Algunas consideraciones en torno al valor patrimonial y a la preservación de las construcciones de piedra del Sistema de Tandilia. En: Patrimonio, Ciencia y Comunidad, editado por M. L. Endere y J. L. Prado, pp. 205-230. INCUAPA-UNICEN y Municipalidad de Olavarría, Olavarría.

Pedrotta, V (2013). Reandando los caminos al Chapaleofú: Viejas y nuevas hipótesis sobre las construcciones de piedra del Sistema de Tandilia. Memoria Americana 21 (2): 269-295.

Pedrotta, V (2016). Estrategias indígenas de captura y manejo del ganado cimarrón en las sierras septentrionales bonaerenses: las construcciones de piedra Cerro Guacho I y Cerro Guacho II. Arqueología 22 (2): 29-49.

Pedrotta, V (2017). Tras las huellas de los jesuitas en las pampas argentinas: la reducción Nuestra Señora de la Purísima Concepción de los Indios Pampas (1740-1753). Trabajos y Comunicaciones 47, e030.

Pedrotta, V. y V. N. Bagaloni (2006). Resultados preliminares del análisis de los materiales vítreos del sitio Arroyo Nieves 2 (Pdo. Olavarría, Pcia. Bs. As.). En: Estudios de Arqueología Histórica. Investigaciones argentinas pluridisciplinarias, editado por $\mathrm{A}$. $\mathrm{H}$. Tapia; $\mathrm{M}$. Ramos y C. Baldassarre, pp. 97-107. Museo Municipal de Río Grande, Buenos Aires.

Pedrotta, V. y V. N. Bagaloni (2020). Arqueología histórica y comunidades locales en la región pampeana: trayectorias, experiencias y perspectivas. Corpus 10 (1): 245-259.

Pedrotta, V., Bagaloni, V. y Duguine, L. (2012). Análisis químicos aplicados a la investigación arqueológica de construcciones de piedra del Sistema de Tandilia. En: Temas y problemas de la Arqueología Histórica, editado por M. Ramos, A. Tapia, F. Bognanni, M. Fernández, V. Helfer, C. Landa, M. Lanza, E. Montanari, E. Néspolo y V. Pineau, Tomo I, pp. 389-404. Universidad Nacional de Luján. Luján.

Pedrotta, V. y Duguine, L. (2013). “¿Muros o Muralla? Evaluando hipótesis acerca de las construcciones de piedra de las Sierras del Azul (Región Pampeana argentina)". En: Arqueología Histórica en Argentina, editado por E. M. Rodríguez Leirado y D. Schávelzon, Tomo I, pp. 87-110. Editorial Académica Española, Saarbrüken.

Pedrotta, V. y Lanteri, S. (2020). ¿Indios amigos o pobladores criollos? Las solicitudes de tierras de los Maicá en Buenos Aires a principios de 1860s. Mundo Agrario 21(48).

Pupio, A. y Tomassini, H. (2020). Tomar la fábrica, recuperar la historia. Memorias, paisajes y patrimonios en un frigorífico recuperado (Bahía Blanca, Argentina). Revista del Museo de Antropología 13 (3): 39-52.

Ratto, S. (2001). El debate sobre la frontera a partir de Turner. La New History, los Borderland y el estudio de las fronteras en Latinoamérica. Boletín del Instituto Ravignani 24(2):105-126.

Tomassini, H. (2020). Estructuras defensivas de cavado (Bahía Blanca, siglo XIX). Un abordaje desde la

Arqueología histórica en el espacio fronterizo y rural pampeanopatagónico: trayectorias, avances y desafios

Páginas 27-45
V. Pedrotta, V. Bagaloni, B.A. Pollard,

I.C. Bracco, J.R. Tormo Izaguirre, H. TOMASSini, A.C. Eliges y V.S. Martí 
Geoarqueología y la Arqueología Histórica. Vestígios 14 (1), 3-24.

Tomassini, H. y Weimann, J. (2020). Análisis de materiales de loza del sitio Boliche Lucanera (Gral. Daniel Cerri, partido de Bahía Blanca). La Zaranda de Ideas 18 (2), 40-58.

Recibido: 30 de marzo de 2021

Aceptado: 10 de mayo de 2021

Arqueología histórica en el espacio fronterizo y rural pampeanopatagónico: trayectorias, avances y desafios Páginas 27-45
V. Pedrotta, V. Bagaloni, B.A. Pollard, I.C. Bracco, J.R. Tormo Izaguirre, H. Tomassini, A.C. Eliges y V.S. Martí 